\title{
Angela Carter lectrice de Colette, ou les affinités électives
}

Martine Hennard Dutheil de la Rochère

\section{(2) OpenEdition}

1 Journals

Édition électronique

URL : http://journals.openedition.org/edl/2397

DOI : $10.4000 /$ edl.2397

ISSN : 2296-5084

Éditeur

Université de Lausanne

\section{Édition imprimée}

Date de publication : 15 mars 2020

Pagination : 141-146

ISBN : 978-2-940331-73-4

ISSN : 0014-2026

Référence électronique

Martine Hennard Dutheil de la Rochère, «Angela Carter lectrice de Colette, ou les affinités électives », Études de lettres [En ligne], 312 | 2020, mis en ligne le 24 mars 2020, consulté le 17 septembre 2020 URL : http://journals.openedition.org/edl/2397 ; DOI : https://doi.org/10.4000/edl.2397

(c) Études de lettres 


\section{ANGELA CARTER LECTRICE DE COLETTE, OU LES AFFINITÉS ÉLECTIVES}

1979 fut une année décisive pour l'écrivaine britannique Angela Carter. Cette année-là, elle publie deux ouvrages qui vont marquer un tournant dans sa carrière: The Bloody Chamber and Other Stories, qui revisite les contes familiers dans un style baroque, allusif, sensuel et chatoyant, et The Sadeian Woman: An Exercice in Cultural History, un essai polémique sur Sade comme "pornographe au service des femmes». Alors que l'essai fait scandale dans les milieux féministes «radicaux», les réécritures de «La Barbe bleue», «La Belle et la Bête» et «Le Petit Chaperon rouge» vont donner une nouvelle actualité aux contes et marquer durablement la culture anglaise.

L'originalité de l'œuvre de Carter doit beaucoup à son goût précoce pour la littérature française, qu'elle découvre à l'adolescence avec Baudelaire. Même si son engagement féministe tempère par la suite sa ferveur pour l'auteur des aphorismes de Fusées, elle ne reniera jamais ses premières amours. L’enseignement universitaire de la "great tradition" l'ennuie, et elle s'en détourne pour explorer des traditions plus marginales ou étrangères. Elle rejette aussi avec force la pruderie et l'hypocrisie puritaine, de même que le dogme du réalisme socialiste de rigueur dans les milieux de la littérature féministe et progressiste autoproclamée. Contre ces diverses formes d'orthodoxie, elle lit assidûment les écrivains de la transgression, les romantiques "noirs", les décadents et les surréalistes - autant de lectures buissonnières à partir desquelles elle va façonner sa propre poétique et politique. De fait, son goût pour la langue et la littérature françaises, qu'elle s'approprie par la traduction, est intimement lié à sa démarche d'écrivain et à l'élaboration de sa propre écriture, car elle 
est convaincue que le développement intellectuel passe par la (re)lecture créative et critique des textes du passé.

Sans surprise, Colette figure parmi les "French connections" de Carter. Et pourtant, les spécialistes de son œuvre ont ignoré les liens étroits tissés avec cette figure libre, rebelle et insoumise de la Belle Époque. En témoigne un long article, intitulé simplement "Colette", paru dans The London Review of Books le 2 octobre 1980. Publié à l'occasion de la récente biographie de Michèle Sarde et de la réédition de l'œuvre de l'écrivaine française chez Penguin, sous la forme de petits volumes habillés de couleurs pastel rose tendre, mauve et vert amande (comme les petites culottes de Léa, observe Carter avec malice), l'article s'attache à la façon dont Colette a su trouver sa voie et créer son propre mythe. Il dénote une connaissance intime et étendue de sa vie et de son œuvre et montre comment l'auteure française incarne une liberté de mœurs durement conquise ainsi qu'une mobilité sociale qui va de pair avec l'accès des femmes à une relative indépendance économique, puis à la reconnaissance littéraire et académique. Les romans de Colette ont aussi joué un rôle libérateur pour plusieurs générations de lectrices, notamment par rapport au désir et au plaisir.

Carter souligne que Colette s'est forgé un nom (à la fois prénom et surnom), et elle salue la liberté de cette femme émancipée qui fait fi des convenances et affirme son identité d'écrivain dans l'entre-deux-guerres, depuis sa carrière d'artiste de music-hall, bisexuelle et scandaleuse, jusqu'à sa nomination à l'académie Goncourt et ses funérailles nationales. Elle s'intéresse aussi à la démarche semi-autobiographique amorcée dans les aventures de Claudine sous l'impulsion de Willy, puis affinée de livre en livre. Son œuvre tout entière, de son enfance campagnarde à ses amours tumultueuses, participe d'une extraordinaire mise en scène de soi (ou self-fashioning) à travers l'écriture. Carter est donc cette "hypocrite lectrice de Colette, sa semblable, sa sœur ", dans laquelle elle se projette et qu'elle cherche à la fois à émuler et à démasquer. L'article note son inépuisable énergie et sa capacité de séduction, y compris par l'écriture, qui doit beaucoup à son expérience de comédienne et de mime dénudée: Colette a l'art de se mettre en scène dans ses récits ("a peculiar kind of literary strip-tease»), et cette intimité jouée est artistiquement construite, calculée, consciente d'elle-même et de ses effets. Autrement dit, Carter met en évidence une forme de "performance» de soi indissociable de la 
démarche littéraire et artistique de Colette (et constitutive de son ethos d'écrivain).

The Bloody Chamber peut même se lire comme un hommage crypté à l'auteure française, tant au niveau de l'intrigue que du point de vue narratif, thématique et même stylistique. On retrouve une même attention aux détails, aux jeux de lumière sur le mur d'une chambre, aux saveurs subtiles et gourmandes d'un repas fin, à la caresse d'un déshabillé de soie, ainsi qu'au dangereux ballet de la séduction et du piège de la volupté. Cette version Belle Époque de "La Barbe bleue», située entre Paris et la Bretagne (en écho à Rozven et au Blé en herbe?), semble même émuler la technique d'écriture de Colette décrite dans l'article. La jeune épouse à peine nubile (une nouvelle Claudine?) narre avec force détails ses noces avec un marquis richissime (un mélange de Willy, jouisseur et mondain, et de Jouvenel, l'intellectuel aristocrate?) jusqu'à la découverte de son macabre secret, suivi de l'heureux dénouement grâce à l'intervention in extremis de la mère de la jeune femme (une nouvelle Sido ?). À l'instar des narratrices ambiguës de Colette, la jeune femme s'attarde sur les détails scabreux de la relation sadomasochiste nouée avec son époux pervers et manipulateur jusque dans l'intimité de la chambre nuptiale. Cette variation "gothique», "horrifique» et "décadente» de "La Barbe bleue", outre les lointains échos à la vie de Colette, tient de l'hommage et du pastiche. Cette présence de Colette est d'ailleurs confirmée dans une lettre à Elaine Jordan où Carter souligne sa volonté de rendre hommage à l'auteure de Chéri:

I wanted a lush fin-de-siècle decor for the story, and a style that [...] utilizes the heightened diction of the novelette, to half-seduce the reader into this wicked, glamorous, fatal world ${ }^{1}$.

Carter souligne ici toute l'ironie du malentendu culturel, littéraire, intellectuel et idéologique qui se joue dans la réception de The Bloody Chamber: les féministes anglo-américaines récusent un récit qui se veut un hommage à une figure pionnière de l'émancipation féminine dans les mœurs comme dans l'histoire littéraire. Carter se réclame en effet de l'héritage de Colette, qui a libéré la parole des femmes (y compris la sienne), sans pour autant être dupe de sa posture d'auteure. Carter ne cache d'ailleurs pas son admiration pour cette capacité à se créer un

I. E. Jordan, «The Dangerous Edge», p. 197. 
personnage et termine l'article en saluant l'exceptionnelle audace de la démarche de l'écrivaine.

Que dit Carter, à travers Colette, en cette "première année du monde contemporain"? À l'évidence, lorsqu'elle publie l'article en 1980, Carter s'interroge sur ce que signifie une carrière littéraire au féminin. Plus généralement, elle témoigne de ses affinités avec une femme écrivain qui, comme elle, ne se reconnaît pas dans l'orthodoxie féministe de son époque. L'une et l'autre sont des femmes émancipées qui ont su se réinventer tout au long de leur vie en fines observatrices des rapports humains, du désir et de "ces plaisirs qu’on nomme, à la légère, physiques", sans fausse pudeur ni faux-semblants - ni complaisance visà-vis d'elles-mêmes. Carter, à travers Colette, anticipe aussi un intérêt pour le queer et pour l'idée de la production de soi qui annonce les théories de l'identité performative de Judith Butler, dans la mesure où elle s'intéresse à la construction d'une identité féminine qui ne se plie pas aux conventions sociales et dépasse les oppositions de genre comme de sexe (l'androgynie de Colette, ses amours au féminin et au masculin, ses jeunes amants, etc.). L'intérêt manifeste de Carter pour des figures de femmes fortes, indépendantes et résilientes, ayant su gagner leur autonomie malgré les contraintes sociales et les aléas de la vie, revendiquant leur liberté avec gaieté, lucidité, talent, courage et humour, se démarque des discours victimaires, pudibonds et moralisateurs.

Quelques années plus tard, elle fait un clin d'œil complice à Colette dans Nights at the Circus (1984), lorsque son héroïne extravagante, la trapéziste ailée Fevvers, en tournée avec le cirque du Colonel Kearney, dîne avec Colette et Willy lors de son passage à Paris. Carter rendra un dernier hommage à Colette en incluant «Rainy Moon" ("La Lune de pluie») dans Wayward Girls and Wicked Women: An Anthology of Subversive Stories (1986), qui rassemble des récits de personnages féminins rebelles qui refusent le statut de victime et prennent leur destin en main, à l'image de leurs auteures (Leonora Carrington, Bessie Head, Suniti Namjoshi, Luo Shu...).

À travers le dialogue noué avec Colette, on mesure à la fois les continuités et les écarts, voire les ruptures, entre les féminismes d'hier et d'aujourd'hui.

Martine Hennard Dutheil de la Rochère Section d'anglais, Faculté des lettres, Université de Lausanne 


\section{BIBLIOGRAPHIE}

Carter, Angela, The Sadeian Woman: An Exercice in Cultural History, London, Virago, 1979.

-, The Bloody Chamber and Other Stories, London, Victor Gollancz, 1979.

—, "Colette», The London Review of Books, II/19 (2 October 1980), p. 15-17.

—, Nights at the Circus, London, Chatto \& Windus, 1984.

- (ed.), Wayward Girls and Wicked Women: An Anthology of Subversive Stories, London, Virago, 1986.

Jordan, Elaine, "The Dangerous Edge", in Flesh and the Mirror: Essays on the Art of Angela Carter, ed. by Lorna Sage, London, Virago, 1994, p. 189-215. 
